\title{
ALGUNOS COMENTARIOS ACERCA DE LA ENSEÑANZA DE LA HISTORIA DE COLOMBIA
}

\author{
Alfredo Cabana O. \\ César A. Vera G.
}

El avance de la sociedad contemporánea en sus aspectos técnicos, que encierra los logros en la modernización de los instrumentos de trabajo y el aprovechamiento de los recursos que brinda la naturaleza, ha influido notablemente en la orientación de las preocupaciones del hombre de la sociedad a la cual pertenece, deteniéndose especialmente en las situaciones de conflicto, como: si la producción de alimentos, vestidos, vivienda, etc., son o no suficientes en un momento dado, o si las llamadas necesidades materiales son consideradas no sólo de atención prioritaria sino de tratamiento exclusivo, sin que otras necesidades que podríamos llamar intelectuales, culturales, artísticas, que afronta el hombre del siglo XX sean objeto del tratamiento que requieren.

Esto ha contribuido a que se hable de una deshumanización o una crisis del humanismo, observado claramente en la poca producción y avance en el campo de las ciencias sociales y en el comportamiento del hombre en sociedad. Estamos invadidos por esa concepción de tecnicismo que quiere reducir la sociedad a esquemas rígidos en los cuales el proceso de desarrollo de la sociedad y su propia dinámica son consideradas como algo accidental y secundario; el hombre es aislado en su perspectiva históricosocial, reducido a simples modelos de comportamiento que tratan de ubicarlo en situaciones con fines determinados como consecuencia de esa jerarquía manifestada a través de las diferentes preocupaciones propias de nuestra sociedad.

Las consideraciones anteriores nos llevan a plantear situaciones muy concretas si las trasladamos al problema educativo colombiano. Hoy observamos una gran despreocupación por las Ciencias Sociales, materializada en la reducción de la intensidad horaria en escuelas y colegios; en la relegación a planos secundarios de su importancia; en los petrificados métodos de enseñanza donde opera el discurso, en muchos casos de baja calidad y las formas obsoletas de heroicidad en el tratamiento de nuestros hechos históricos, al lado del rigor cronológico y la división acomodaticia de buenos y malos personajes.

El presente artículo de ninguna manera pretende agotar el tema que se aborta. El objetivo fundamental es: mostrar que la enseñanza de la Historia de Colombia ha sido tratada en forma poco científica y que no se le ha dado la importancia que en realidad merece. Además, destacar la labor que desarrollan nuevos investigadores al presentar un nuevo enfoque de la enseñanza y de la investigación histérica.

Si iniciamos el análisis a partir de la escuela primaria, hasta recordar los contenidos que nos fueron transmitidos cuando cursábamos esta etapa de la enseñanza. Desde el primer grado nos saturaban de conocimientos memorísticos, como los de las fechas de las batallas, el nacimiento de los héroes, las fundaciones de los conquistadores y otra serie de hechos inconexos, que en lugar de proporcionarnos elementos para iniciarnos en la comprensión del proceso histórico de sus fuerzas motrices y de sus leyes; nos confundía y nos presentaba una imagen abstracta y mutilada del mencionado proceso. 
En el anterior marco de ideas podemos ubicar las causas a que obedece la orientación dada a la Historia de Colombia, en la escuela primaria y por supuesto en la enseñanza secundaria.

La historia y en general todas las ciencias sociales poseen un carácter emancipador, proporcionan al hombre elementos de juicio para comprender la realidad y tomar conciencia de su papel en el proceso de su transformación. Debido a esto, la historia ha sido enseñada con criterios de interpretación heroica y episódica, evidenciándose la ausencia absoluta de análisis crítico. Por medio de ella se ha querido dar a los alumnos una visión distorsionada y muchas veces falsa de nuestro proceso histórico obviamente derivada de los intereses de las clases dominantes de darse una imagen de legitimidad", "rectitud' y 'justicia". Cabe aquí la apreciación presentada por un joven historiador: 'Unilateral, parcializada y anticientífica ha sido gran parte de la versión que hemos recibido del pasado nacional"1.

Ahora bien, en el aspecto meramente didáctico, el texto de Historia ha sido el recurso mayormente utilizado para transmitir los conocimientos y se ha convertido en una verdadera camisa de fuerza, tanto para el alumno como para el profesor, no permitiéndoles desarrollar una labor investigativa. Dichos textos no hacen otra cosa que reflejar la interpretación clerical y heroica de la historia. Sobre lo anterior comenta Darío Jaramillo: "Aunque es cierto que la cartilla o manual de historia es lo primero del pasado colombiano que enfrenta cualquier estudiante de escuela primaria, ellos son un resultado final de la investigación histórica, una especie de estracto destilado con el exclusivo propósito de torturar la memoria y simultáneamente adormecer el sentido crítico y la imaginación de los estudiantes"2.

Es a nivel de enseñanza universitaria donde se está adelantando una verdadera labor de investigación cien-Lítica de la Historia Colombiana (aunque no en todas las universidades) y se está enseñando con un sentido analítico-critico.

Es allí donde han surgido investigaciones como las de Jorge Orlando Melo, Germán Colmenares, Alvaro Tirado mejía, Francisco Posada y muchos otros autores que cita Jaramillo A, en la Introducción mencionada y que han dado una nueva orientación a los estudios históricos, haciendo caso omiso de la simple relación de hechos políticos y militares. Otra de las tendencias que ha tomado gran auge últimamente, es aquella de inspiración positivista, que como se dijo inicialmente, pretende reducir la Historia y toda la realidad social a unos datos escuetos, aislados de toda relación con el contexto social. Esta manifestación obedece a la implantación de modelos importados que quieren dar mayor importancia a la técnica que a cualquier tipo de análisis. Acerca de esto conceptúa E. Zuleta: "El hombre de la técnica se enfrenta al mundo como un objeto inmediatamente dado para su cuantificación, clasificación y manipulación. Cuando se trata de realidades sociales y económicas pretende conservar la misma actitud y produce una sociología y una economía en las cuales la descripción horizontal y la cuantificación han reemplazado las exigencias de comprender y explicar y con el orgulloso pretexto de haber cambiado las

\footnotetext{
${ }^{1}$ RODRIGUEZ ACOSTA, Hugo. "Elementos críticos para una nueva interpretación de la Historia Colombiana". Editorial Tupac Amarú, 1973, pag. 9.

2 JARAMILlO AGUDELO, Darío. "La nueva historia de Colombia", Bogotá, Instituto Colombiano de cultura, Biblioteca Básica Colombiana, vol. 18, pag. 8. 
vagas especulaciones filosóficas por la estadística, se abandona en realidad la crítica y la historia en la consideración de los hechos humanos ${ }^{3}$.

Este breve artículo que abordé un tema que debe ser objeto de una investigación más profunda, quiso presentar unos lineamientos sobre lo que fue la enseñanza de la historia, que en opinión de Maurice Godelier es la ciencia que "moviliza y unifica todas las ciencias humanas"; hasta que investigadores con un nuevo método y otras concepciones científicas, dieron duro golpe a la historia que podríamos llamar "oficial ".

\section{RESEÑAS}

\footnotetext{
${ }^{3}$ ZULETA, Estanislao. “Conferencias sobre Historia Económica de Colombia”. Editorial La Oveja Negra, Bogotá, pág.
} 7. 
Las reseñas que aparecen en este primer número de la Revista son el reflejo de la política Investigativa y de la actividad que se adelanta actualmente en el Centro de Investigaciones de la Universidad Pedagógica Nacional*.

Cada una de ellas, está bajo la responsabilidad técnica de un coordinador y un grupo de técnicos vinculados a la Institución.

Estas investigaciones se financian con los dineros que le han sido apropiados por Presupuesto Nacional a la Universidad Pedagógica Nacional para investigación y a los aportes que se han obtenido de parte del Ministerio de Educación Nacional, Oficina Sectorial de Planeamiento Educativo.

Algunas de las investigaciones se encuentran en la etapa inicial de su ejecución y otras ya están por terminarse. Estos adelantos los podemos observar en las reseñas mismas.

* El Centro de Investigaciones funciona en la Avenida 46 Bo. 15-99. Tels.: 2842091 - 2455624. 